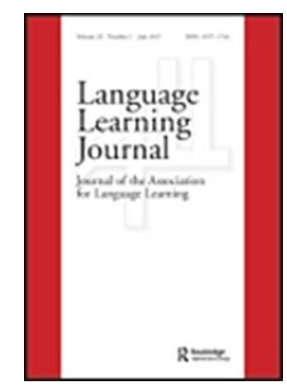

The impact of the 'writers' workshop' approach on the L2 English writing of upper-primary students in Lebanon

\begin{tabular}{|r|l|}
\hline Journal: & The Language Learning Journal \\
\hline Manuscript ID & RLLJ-2015-0036.R3 \\
\hline Manuscript Type: & Original Paper \\
\hline Keywords: & $\begin{array}{l}\text { writer's workshop, writing components, peer editing, mini-lesson, drafting; } \\
\text { revising }\end{array}$ \\
\hline \multicolumn{2}{|l}{} \\
\hline
\end{tabular}

SCHOLARONE ${ }^{m}$

Manuscripts

URL: http://mc.manuscriptcentral.com/rllj Email: N.Pachler@ioe.ac.uk 
The Impact of the Writers' Workshop Approach

\title{
The impact of the 'writers' workshop' approach on the L2 English writing of upper-primary students in Lebanon
}

\begin{abstract}
The aim of the action research reported here was to examine the differential effects of the 'writers' workshop' approach on the L2 (English) writing skills of upper-primary students with varying writing abilities. The participants were 31 fifth-grade students (17 boys and 14 girls) aged 10-11, who followed L2 English writing instruction based on the 'writers' workshop' approach at a private primary school in Beirut, Lebanon. The writers' workshops were conducted twice a week over a period of eight consecutive weeks. An opinion essay served as a pre-test and a post-test in order to gauge writing improvement. Findings revealed statistically significant improvement in students' writing-related outcomes across all writing ability groups. However, the writers' workshops intervention was found to result in a differential group effect: generally, above-average writers benefitted more than less proficient writers. This was particularly clear in relation to the content component of their essay writing.
\end{abstract}

\section{Keywords}

Writers' workshop; writing components; peer editing; mini-lesson; drafting; revising

\section{Introduction}

The 'writers' workshop' model was first developed by Graves (1983) as a process-oriented instructional approach to help students with limited English language proficiency in mainstream US schools. ${ }^{1}$ It is a student-centred model insofar as student writers are helped to explore their writing abilities and to write about personal and meaningful topics (Calkins 1994). The main elements of the model emphasise the process of writing, frequency of writing, student decision-making, interactions with fellow students, sharing work with the teacher and other students, as well as direct instruction (Harris, Graham and Mason, 2006). Calkins (2007) describes the writers' workshop approach as a predictably scheduled time for participating in writing, which involves a teachercentred mini-lesson (10-15 minutes), then an individual progress check (5 minutes), followed by independent writing and conferring (20-25 minutes), and finally, group sharing (5 minutes). Such a learning environment aims to allow students to take charge of their own writing (Fletcher and Portalupi, 2004) and to take risks (Sheakoski 2008). Learners are said to experience, learn and practise a cyclical process of topic selection, drafting/revising, editing and publishing their 
pieces of writing, determining their own pace throughout (Calkins, 1994; Harris et al. 2006). It is argued that, in this way, they experience writing as 'real writers' do (Calkins, 1994).

Proponents of the writers' workshop approach claim that the approach is 'authentic' in the sense that it involves engaging learners in activities and practices demonstrated by skilled writers. The underlying principle underlying the approach is that the opportunities to participate in social discourse at all stages of the process - before, during and after task completion - provides students with a broader formative basis of support for the development of their writing. Such discourse, it is argued, helps them express their ideas, ask questions and categorise concepts (Goodman and Wilde 1992) which in turn feeds into their writing output. However, in the context of young school learners and in particular those writing in a second or foreign language in which they have variable mastery, such claims and goals may seem over-ambitious. Empirical evidence is needed to see to what extent the framework provided by this instructional strategy is conducive to developing language and writing competence even in such learners.

The concept of 'process-oriented instructional approach' referred to at the start of this paper as part of the definition of the writers' workshop model needs to be understood in the context of the distinction made in the literature between 'product-oriented', 'process-oriented' and 'genre' approaches to writing pedagogy. The product-oriented writing approach emphasises linguistic knowledge, focusing on grammatical and syntactical structures mainly involving the imitation of written material supplied by the teacher (Badger and White 2000; Rogers 2010). The process-oriented writing approach, on the other hand, shifts the focus from linguistic knowledge to linguistic skills, including how to plan, draft and revise a piece of writing, and emphasises the subject matter, ideas, and the negotiation of meaning involved in written communication (Badger and White 2000). Process writing can exist in a range of forms: for example, the writers' workshop approach, and production of reflective journals/diaries or learning logs (Smithson 2008).

The process-oriented approach, however, has been increasingly challenged by genre-oriented scholars (e.g. Atkinson 2003; McComiskey 2000; Smagorinsky et al. 2010) who contend that writing cannot be only a set of cognitive abilities because it provides a means for individuals to connect with each other in ways that hold specific social significance. The teaching of major genres, therefore, can help EFL/ESL learners to communicate effectively in ways that have amassed cultural capital, in other words, a resource which equips learners with knowledge and practical skills in the educational system (Bourdieu and Passeron 1990), in certain communities (Hyland 2003). While a genre approach shares many features with a product cycle, the fundamental difference is that the former focuses on the purpose of the writing and the use of authentic materials to consciously analyse the vocabulary, grammatical structures and cohesive devices employed in the text. However, a criticism is that these genres inhibit writers' self-expression and creativity if they feel constrained by a prescriptive approach (Bitchener 2010; Rogers 2010). Furthermore, several researchers (e.g. Dyer 1996;

URL: http://mc.manuscriptcentral.čm/rllj Email: N.Pachler@ioe.ac.uk 
The Impact of the Writers' Workshop Approach

Tangpermpoon 2008) have argued that these all these approaches offer complementary perspectives, rather than mutually exclusive viewpoints.

While in its original conception the writers' workshop was developed primarily as a process-oriented pedagogical strategy for use with first and second language learners in the USA, the language learning needs of all L2 students are no doubt best met by an approach that combines a focus on both process and product in writing. The study described in this paper, therefore, adopted an integrated, or 'hybrid', process-product approach, so as to allow the students to study the relationship between purpose and form as they used the recursive processes of prewriting, drafting, revision and editing.

The underlying principles of the framework are as follows: producing written text for an audience that includes but is not exclusively the teacher, writing material which covers all curriculum subjects, learning grammar and the 'mechanics of writing' (i.e., conventions relating to spelling and punctuation) while producing actual written work, and a holistic approach to the writing process (Christopher, Ewald and Giangrasso 2000, cited in Smithson 2008). This holistic approach engages learners in a collaborative piece of writing, focusing on both form and content to produce a well-rounded and rich informative text. As implemented in this study, the writers' workshop aimed to focus attention both on the process of writing and on the resulting text, and to exploit both the teacher's and the students' existing knowledge. In some ways, the principles and applications of the writers' workshop approach echo those of task-based language teaching (TBLT) in the second language teaching context. There is the same focus on the completion, in groups, of an authentic task and the same view that a primary focus on meaningful content can foster effective language learning (Ellis 2009). Where the two approaches diverge, however, is that the writers' workshop approach focuses exclusively on the development of writing skills and proposes the use of mini-lessons as part of the induction stages of the writing process.

\section{Review of the literature}

Graves and Calkins's work on the writers' workshop is regarded as making a pioneering contribution to theory (Pritchard and Honeycutt 2008) and as having provided valuable research evidence (Jasmine and Weiner 2007; Harris et al. 2006). However, as Smagorinsky (1987) earlier pointed out, the limited casestudy methodology that Graves and his colleagues employed amounted to 'reportage' rather than research. What empirical evidence of the effectiveness of the approach has been provided by other researchers in the field? The following review of more recent studies considers the evidence of effects on students' first and second language writing development.

\section{Effects on writing performance}

Several researchers conclude that the writers' workshop approach offers an effective instructional approach for both L1 and L2 writing. Studies on L1 writing have reported positive effects with struggling writers at elementary (primary) 
The Impact of the Writers' Workshop Approach

schools in the US (Baker 1994; Tompkins 2002). Honeycutt (2002), for example, found that fifth-grade students, identified as good readers but poor writers, were particularly receptive to the approach and that gains in writing were linked to the following factors: internalisation of strategies for prewriting, writing and revising; use of metacognitive self-regulation strategies to monitor the development of a text; and use of strategies for dealing with negative emotions that arise during the composing process. However, other studies provide less conclusive evidence of such positive gains. For instance, Harris et al. (2006) compared the impact of the writers' workshop approach and an approach based on self-regulated strategy development (SRSD) whose aim was to foster development of children's strategic behaviour, knowledge and motivation. The study focused on secondgrade students who experienced difficulty in learning to write. Those in the writers' workshop showed less growth in their writing development than those working within the SRSD approach. Helsel and Greenberg (2007), meanwhile, found that the writers' workshop approach enabled many students to progress well but struggling students were unable to manage the independence that was associated with the writing process and failed to make progress. Helsel and Greenberg argue that some students may not reach their potential in the writers' workshop environment alone and that to meet their needs, other approaches may also be required.

In a review of research on the effectiveness of different writing instruction approaches with learners representing the full range of writers found in typical classrooms (high, average, basic, L2, and special education needs learners), Graham and Perin (2007: 20) found that 'explicit training [of teachers] was a major factor in the success of the process writing approach'. When the teachers had undergone explicit training, the effect on their learners' writing was moderate; but without training, the effect was negligible, apart from those students in grades 4 to 6 (ages are not specified in the study) where the effect was found to be small but significant.

In the Middle-Eastern context, Shehade (2011) investigated the effect of collaborative writing pedagogy (including many key features of the writers' workshop approach) on the L2 English writing of first-semester students at a university in the UAE. There was an overall significantly positive effect on the students' writing, with particular gains in the areas of content, organisation and vocabulary, but not in mechanics and grammar. In conclusion, it seems that a student's individual strengths in writing are a key consideration when evaluating the gains of a writing workshop. Even with structured writing instruction from a trained teacher, the results of the workshop may vary. Consideration of all these different factors therefore needs to be made before any final conclusions can be drawn about the effectiveness of the writers' workshop approach.

\section{Evidence of the effectiveness of the approach: motivational and cultural considerations}

Several studies have reported that the workshop approach has led L1 learners to enhanced enjoyment of, and more positive attitudes towards, writing (e.g., Baker 1994; Jasmine and Weiner 2007). Lo and Hyland's (2007) action research study of

URL: http://mc.manuscriptcentral.com/rllj Email: N.Pachler@ioe.ac.uk 
an English-medium primary school in Hong Kong found that the main benefits of exposure to the writers' workshop approach, which requires students to write on topics related to their personal and sociocultural context, were engagement and motivation of the students, particularly low-achieving writers, in comparison with those following a more traditional mode of instruction. While more proficient writers following the writers' workshop programme showed no significant language-related gains, the authors conclude that they were 'challenged to rethink their previous writing strategies' (Lo and Hyland 2007: 232). Carolina (2009) investigated the writing development of English language learners (ELLS) in a fourth-grade bilingual classroom in Northern California by observing how students developed stories during a writers' workshop. Evidence suggests that the supportive social context allowed students to utilise their diverse linguistic and cultural resources to identify themes and topics when writing stories. The students, who came from both Spanish and English speaking family backgrounds, were comfortable incorporating various abilities and skills which they drew from their family culture and their communities, making their writing more culturally relevant.

However, the writers' workshop approach may present problems for classes with pupils with different cultural backgrounds. Vollmer's research, based on ethnographic fieldwork conducted in a Californian high school, examined the impact of (1) sociocultural factors; and (2) assumptions implicit in the teachers' discourse, on the writing experience of ESL students. The findings demonstrated that many high school teachers who adopted a writers' workshop approach, thereby allowing students a free choice of subject, 'at the same time restrained student writing by ascribing them the sole identity of immigrant from which to develop their topics' (2000: 2). In a subsequent paper, Vollmer (2002) argues that teachers should be aware not only of how student writers endeavour to develop a new identity-and multiple identities - in the second language, but also how practices and assignments in the classroom may impose restrictive identities on the writers. In addition, teachers should recognise that students' autobiographies produced in class are necessarily selective, partial and formed by what is perceived as appropriate for classroom work. Carson and Nelson (1996) produce a different criticism, arguing that the critiquing of other students' written texts (a constituent component of the writers' workshop approach) worked against the collectivist cultural orientation of students from Asian backgrounds. Being an immigrant with the knowledge of two languages may be a factor that needs to be addressed in writing workshops. Bilingual students bring with them a multi-cultural dimension that should not be forced in their writing but could provide them with some inspiration for the writing process in workshops. Students should still be able to freely select their topics whatever their language and social context.

The studies reported in this section are set in the context of schools in second language settings, that is, in settings where the target language is the language of the host community. There is also a need to investigate the effects of the approach in foreign language contexts. Moreover, there is a gap in research concerning the effects of this approach on primary school students with different 
The Impact of the Writers' Workshop Approach

levels of writing proficiency in writing in English as a foreign language. It is these two areas of enquiry that define the context of our study.

\section{The current research}

The study reported in this paper consisted of a small-scale intervention-based action research study whose aim was to explore a new pedagogical approach which might improve students' writing performance.

Several context-specific factors guided the aims of this study and define its potential contribution to research in the broader field of L2 writing. Firstly, in Lebanon, L2 English teaching in schools has tended to be dominated by teachercentred transmission pedagogy; therefore, exploring the impact of a more student-centred approach may generate insights for future foreign language education policy-making in the country. Secondly, the school system's bilingual education framework provides an interesting context in which to investigate the effects of the writers' workshop approach. The participating school is a private, English-medium school where the students are Lebanese nationals with varying levels of proficiency in English (spoken and written) and where Arabic rather than English is the dominant language of communication. However, English is the medium of instruction in almost all subjects. The communicative and genrebased dimensions of process-oriented EFL writing pedagogy, therefore, can potentially carry over from the students' English lessons to those of other subjects (for example, history and geography) where discussion and composition will also be in English.

\section{Rationale}

The rationale for the current study is twofold. Firstly, the review of existing research revealed contradictory findings regarding the effectiveness of the writers' workshop approach in improving the proficiency of young writers writing in their first language. Furthermore, little research has been conducted into the effectiveness of writers' workshops in the foreign/second language (L2) context, especially in Lebanon where using the English language is highly valued and mandated in the curriculum. Secondly, there are contradictory and inconclusive data on the influence of the writers' workshop on different levels of writing proficiency, so further investigation of its value for L2 learners of different writing abilities is needed. The research questions for the study were therefore as follows:

- Does the writers' workshop approach improve the L2 English writing proficiency (comprising 'content', 'organisation', 'vocabulary', 'language use' and 'mechanics', i.e. spelling and presentation) of upper-primary students in a bilingual school in Lebanon?

- Do upper-primary students with different levels of L2 English writing proficiency (classified as 'below average', 'average' and 'above average') benefit differentially from participation in writers' workshops? 
The Impact of the Writers' Workshop Approach

\section{Methodology Participants}

The participants were 31 students (17 boys and 14 girls), aged 10 to 11 , studying at a private primary school in Beirut that combines the Lebanese and American curricula. The language of instruction in all subjects was English, with the exception of social studies, which was taught in Arabic, and Arabic was also taught as a separate subject. Most of the teaching staff members were bilingual in English and Arabic so the school was able to provide a bilingual environment at both classroom and school level. The participants had already been exposed to structured writing processes in their previous classes. They had worked individually or as a group on pre-drafting, drafting and revision procedures; however, they had not experienced the writers' workshop approach. They had five 50-minute periods of English language a week, two of which were assigned for writing. The topic of writing in these classes was usually assigned by the teacher.

\section{Research design}

The study used a pre-test/post-test design. At the start of the pedagogic intervention, the participants were asked to write a short opinion-based essay, and they then wrote a similar essay at the end. Over eight weeks, during their two 50-minute English writing sessions a week, the intact Grade 5 class was taught using the writers' workshop approach. Three proficiency groups were identified on the basis of the writing test achievement scores: below average, average and above average, corresponding to the $33 \%$ and $67 \%$ percentiles $(11,9$ and 11 students respectively). Improvements potentially attributable to the pedagogic intervention were assessed by comparing pre-test and post-test essay scores. The assessment of the test essay is discussed below. It was, unfortunately, not possible to include a control group in the study, given the constraint of conducting the research with an intact class and the limited number of Grade 5 students in the school.

\section{The pedagogic intervention Training the teacher}

The fifth-grade English language teacher who implemented the writers' workshops had a BA in elementary (primary) education with a specialised diploma in teaching English as a foreign language (TEFL). She had six years' experience in teaching primary classes, but no experience of using the writers' workshop approach. An essential step was thus to train her and this was achieved through three 50-minute training sessions. The researchers and the teacher then worked together to plan writing sessions in accordance with the writers' workshop approach and the objectives of the writing curriculum in the school. A member of the research group observed the teacher in three random workshop sessions. Following each observation, the teacher and the observer reviewed the observation. The advisor-researcher also held regular meetings 
The Impact of the Writers' Workshop Approach

with the teacher during the week to discuss the plan and implementation of each workshop session.

\section{Implementing the writers' workshops}

The target writing task was an essay of about two pages and the types of topic included: describing friends, nature and favourite places. Guidance to students aimed at helping them to engage actively in the different stages involved in the writing process: inventing, drafting and revising. The writers' workshop sessions took the following form:

- During each mini-lesson (5-10 minutes), the teacher concentrated on one facet of writing, basing her mini-lesson on the writing skills identified in the school language arts curriculum; for example, use of the past tense, combining sentences, or participation in revision groups, capitalisation and punctuation.

- The teacher presented examples of essays students had written on topics that they had previously chosen to write about in their notebooks.

- The teacher provided oral explanation or further written notes in the students' notebooks, to help students improve their writing.

- Students worked for 30-40 minutes in small groups, independently, or with the teacher, on different stages of the writing process:

(a) Rehearsal: discovering and generating ideas.

(b) Drafting: putting thoughts on paper.

(c) Revision: focusing on the content of the draft and later on spelling.

(d) Editing: editing the writing after conferring with the teacher.

- While the children were engaged in writing independently, the teacher circulated and conferred with students individually and regularly to help them improve their own writing through revising, editing and giving feedback with peers.

- Students shared their writing with the class using the 'author's chair' activity, which was set up for this purpose. The author's chair task was performed by 2-3 students per class. They received feedback on their writing from their peers (5-10 minutes).

\section{Assessing writing skills}

To assess the students' writing, we used the framework developed by Hadley (1993) as it enables a comprehensive criterion-referenced evaluation of writing proficiency. As shown below, it identifies four levels (novice, intermediate, advanced and superior) and focuses on a range of features from the 'mechanical' aspects (such as spelling and the use of punctuation) to more complex aspects of written composition (Hadley 1993). Only the first three levels of proficiency in Hadley's classification were required as no students reached the 'superior' stage. 
The Impact of the Writers' Workshop Approach

- Below average (novice) level, at which students can write very simple paragraphs using very familiar words. Their writing is characterised by frequent errors and misspellings and consists mostly of lists or filling in forms (Hadley 1993). They experience difficulty in mastering writing processes, such as revising and planning (Fink-Chorzempa et al. 2005; Harris et al. 2006).

- Average (intermediate) level, at which students can create comprehensible statements and organised paragraphs that meet practical needs but with limited dictionary skills. Their writings are comprehensible and show good control of basic constructions (Hadley 1993), but do not have a thorough or confident control of grammar. They spend some time in planning and revising (Harris et al. 2006).

- Above average (advanced) level, at which students can write more coherent paragraphs that have formal correspondence, with sufficient vocabulary and good elementary constructions. They reflect good control of language when narrating and giving detailed descriptions (Hadley 1993). These students spend more time in planning and revising (Harris et al. 2006).

All three groups undertook a writing pre-test to determine their writing score at the start of the experiment, based on the five components of writing: content, organisation, vocabulary, grammar, and mechanics. An analytical scoring technique using the ESL Composition Profile was used to score both the pre- and post-tests. This scale was extracted from Hadley (1993; the original version of this profile appeared in Jacobs, Zinkgraf, Wormuth, Hartfiel and Hughey (1981)). It involves focusing separately on different components of a composition and scoring them based on level of proficiency: excellent to very good, good to average, fair to poor, or very poor. The components were content (0-30 marks), organisation (0-20 marks), vocabulary (0-20 marks), language use (0-25 marks), and mechanics (0-5 marks). These components were defined as follows:

- Content: knowledgeable - substantive - thorough development of thesis - relevant to assigned topic.

- Organisation: fluent expression - ideas clearly stated/supported succinct - well-organised - logical sequencing - cohesive.

- Vocabulary: sophisticated range - effective word/idiom choice and usage - word form mastery -appropriate register.

- Language use: effective complex construction - few errors of agreement, tense, number, word order/function, articles, pronouns, prepositions.

- Mechanics: demonstrate mastery of conventions - few errors of spelling, punctuation, capitalisation, paragraphing.

Two English teachers were asked to independently score the pre- and post-tests of each student using the ESL Composition Profile. The inter-rater reliability was calculated for scores on each component, with average agreement being $89 \%$, ranging between $77 \%$ and $99 \%$. The scores of the two raters were then averaged to give each student's final scores. 
The Impact of the Writers' Workshop Approach

\begin{abstract}
Data analysis
Descriptive statistics for each of the five component scores from the post-test were calculated for the whole group and also for each of the three proficiency groups. A MANCOVA test was then used to investigate the effects of the writers' workshop. This was followed by the Bonferroni test, which was applied to assess the significance of pairwise post-hoc differences that existed between the three groups in relation to the five writing components. The Bonferroni test was useful for determining whether there was a group differential effect at the $p<.01$ significance level in order to identify which group benefited most from the workshops.
\end{abstract}

\title{
Results
}

Table 1 shows the mean scores on the five writing components and the overall total for the students' pre-test and post-test essays. Using paired-sample $t$ tests, the six paired scores were compared to determine improvement in students' writing ability between pre- and post-test. For all five paired component scores, there were significant differences between the pre- and post-tests at $p<.01$ level. There was also a statistically significant improvement in total scores [ $t$ (30) $=-8.20, p<.01]$.

\section{< Insert Table 1 about here >}

Table 2 presents the means, standard deviations and MANCOVA of the post-test scores for the three proficiency groups. The MANCOVA was conducted to test whether the writers' workshop approach was effective in improving the writing of each of the three groups. It confirmed a statistically significant difference at the $p<.01$ alpha level between the pre-test and post-test total mean scores $[F(25.42), p=.00]$.

\section{$<$ Insert Table 2 about here >}

Post-hoc Bonferroni was also used to investigate whether the writers' workshop treatment might have had a differential effect on the student writers depending on their proficiency level. The results of the post-hoc Bonferroni test are reported in Table 3. This focused on whether there were significant proficiency group differences in post-test scores at the $p<.01$ alpha level. Significant differences were found in the mean scores of the below-average and the above-average groups on all components. The below-average and the average groups differed significantly on content, vocabulary and language use, while the average and the above-average groups differed only on vocabulary and organisation. The mean differences between below-average and average were $M D=4.20$ (in favour of the average group), and between below-average and above-average $M D=6.00$ (in favour of the above-average group). Bonferroni tests showed that the most significant difference between the three groups was 
The Impact of the Writers' Workshop Approach

that between the below-average and above-average groups in relation to content at the $p<.01$ alpha level.

< Insert Table 3 about here >

\section{Discussion}

The first research question in this study concerned the effects of the writers' workshop approach on students' writing in the class as a whole. It was expected that there would be significant improvements in students' writing, since the writers' workshop approach was designed to support students' writing development through a cooperative learning environment. Our results in principle indicated that the writers' workshop approach had an impact on the participants' writing, regardless of proficiency, in that there were significant improvements in average scores between pre-test and post-test on all five writing components, as well as on total scores. However, it should be remembered that given the absence of a control group in our research, we cannot confidently attribute the difference in pre- and post-test results to the writers' workshop treatment alone.

Nevertheless, our results are consistent with those of Baker's (1994) and Honeycutt's (2002) studies, which found that the scaffolded instruction provided through the writers' workshop approach supports improvement in students' writing skills. Such findings chime with Vygotsky's (1978) constructivist perspective on learning; when children, or novices, use imitation in collective activities under more expert guidance, they can do things beyond their actual capabilities. Assistance, imitation and co-operation are significant factors in providing the appropriate tools for higher mental functioning.

The second research question focused on whether upper-primary students with different levels of writing proficiency benefit differentially from the writers' workshop approach. Bonferroni tests indicated that there were significant mean differences in the mean scores of the three groups on all five writing components, the greatest difference being between below-average and aboveaverage students on content. The results showed that the approach seemed to have a stronger impact on students in the above-average group than on those in the average and below-average groups on all five writing components.

This difference in impact could be attributed to the fact that the aboveaverage students were able to write coherent paragraphs with formal correspondence, sufficient vocabulary and 'effective complex construction of language use with few errors' (Hadley 1993). This may have helped them to meet the multiple cognitive and self-regulatory demands of the writing process with the assistance of the teacher more effectively than was the case for beginning writers (Dorn and Soffos 2001). As they gain ownership of their writing through the workshop process (Ray and Laminack 2001), advanced students can reflect on the direction their writing will take and effectively plan their work. Thus the process of revision arguably works more smoothly for more proficient writers 
because they have developed control of the mechanics of writing and can devote their attention to content and style (Dorn and Soffos 2001).

The smallest significant mean difference was between below-average and above-average groups for the mechanics component. There were no significant differences between the average and above-average groups' improvement in content, language use and mechanics and no significant difference between average and below-average groups' improvement in organisation, vocabulary and mechanics.

The negative results concerning the below-average group could be attributed to the fact that struggling writers can write only very simple paragraphs using very familiar words. They experience difficulty in mastering writing processes, such as revising and planning (Fink-Chorzempa et al. 2005; Harris et al. 2006). According to Dorn and Soffos (2001), such writers struggle to find terms to express their ideas sequentially while dealing with the mechanical limitations. They risk becoming passive because they may not have the necessary strategies, knowledge and skills to work more independently. Understanding ideas, using expressive language and developing presentational skills are all part of the cognitive process involved in the act of writing. It appears that struggling writers may need direct instruction in building editing skills and refining their ability to compose more sophisticated texts. It may be, therefore, that the collaborative and more open framework of the workshop approach did not provide the most appropriate environment for the below-average group to address these challenges.

These findings are consistent with those of Harris et al.'s (2006) study, which showed that in the case of students experiencing difficulties in writing, the writers' workshop approach was less successful than the SRSD approach. Similarly, Helsel and Greenberg's (2007) study reported that struggling students faced difficulty in how to integrate the full range of cognitive and self-regulatory demands involved in the writing process. Our findings also echo those of Chien (2006) which showed that average and above-average writers benefited more in terms of reviewing, drafting/editing and revision (i.e. in metacognitive processes) than did below-average writers.

The effective use of mini-lessons and editing sessions in the writers' workshop might explain students' improvements, respectively, in grammar and organisation. Developing a sense of audience, through reading out compositions to peers and giving feedback on others' writing, should have helped students to organise their writings more effectively into an introduction, body and conclusion, together with elaboration of the important points. It has been argued that the student-centred nature of writers' workshops helps students to discover what they want to write about in a cooperative environment. They determine the pace of their writing, and thus become motivated to write more coherently (Calkins, 1994; Harris et al. 2006). This is supported by Graves's (1985) findings that, as students become aware of their audience, they begin to use more sophisticated vocabulary and add more description to their writing, which results in longer sentences. Students thus move from writing for themselves to writing for an audience, with positive effects on the language and style of their writing.

URL: http://mc.manuscriptcentral.com/rllj Email: N.Pachler@ioe.ac.uk 
The Impact of the Writers' Workshop Approach

Progress in presentational skills was marked by improvement in the students' ability to edit their writing resulting from the processes of conferring, peer revision and editing. Students' mechanical errors were reduced; their spelling improved and they started punctuating more correctly. Although students became more careful in capitalising and punctuating the ends of sentences following the writers' workshop, mini-lessons and peer revision, the level of improvement was not significant. This finding is echoed in previous studies (e.g., Dix 2006; Graves 1985; Tompkins 2002), indicating that the primary benefit of the writers' workshop consists of engagement in social interaction, permitting work in an atmosphere of co-operation, sharing ideas, and giving responses and feedback, which is arguably conducive to writing development.

Struggling writers, however, may lack the necessary strategies, knowledge and skills to help themselves. Thus direct instruction and guidance from the teacher may be necessary to help emergent writers build editing skills. It is important then, in classes where there is variation in writing proficiency, that teachers offer a range of opportunities to learn about writing, both teacher-led and student-initiated (Dorn and Soffos 2001).

\section{Conclusion, implications and limitations}

In conclusion, our research suggests that the writers' workshop model may have some value in helping to improve the writing proficiency of elementary students writing in a second language, here L2 English elementary students in Lebanon. All students wrote more fluently after the pedagogic intervention, and helped each other through peer interaction to add detail and to edit their writing. The statistical results suggest, however, that above-average students benefited more than average and below-average students from the writers' workshop approach, especially in terms of content. This may be because more proficient students benefit from the scaffolding offered during revision, and conferring, but also from working on self-selected topics of specific interest while less proficient students need greater assistance from the teacher in the form of mini-lessons.

Success in using this pedagogical approach in the Lebanese English immersion classroom and the feasibility of extending its impact to other subjects in the curriculum where English writing is developed suggests that there is potential for incorporating the pedagogy within a CLIL framework. To our knowledge this has not yet been researched.

Several research and practical implications can be drawn from this study. Further investigation is clearly needed to verify our findings, particularly as we were unable to check our improvement results against those of a control group and the numbers in each of the three proficiency groups in the intact class were small. To further strengthen the generalisability of the findings, research needs to be undertaken in a wider range of educational contexts. Longer-term studies would be helpful to explore whether, and how, writers' workshops implemented over a longer period might improve the writing abilities of students across the ability range, particularly below-average students. Studies with a more qualitative focus, using, for instance, journals and focus groups, are needed to 
The Impact of the Writers' Workshop Approach

explore just how students and teachers experience learning through the writers' workshop approach.

There is also a need to investigate how the ESL Composition Profile could be made more effective in discriminating between proficiency levels within this age group (10-11 years). Different weightings are assigned to each subscale; for example, content is weighted as the most important scale and mechanics the lowest. As Ghanbari et al. (2012) have argued in the context of the assessment of EFL learners in Iran, this differential weighting may not provide an adequate framework to account for the needs and capacities of young EFL learners in different settings; the Profile may need, therefore, be adapted to reflect the specific context of language learning.

For practitioners, the present study offers some empirical evidence that the writers' workshop approach may be useful with elementary writers in a second language context, but it also reminds teachers that they need to think carefully about how different aspects of the approach may support learners in classes with mixed abilities.

\section{Note}

1. In the US school system, these students may be referred to as ELLS (English-language learners) while in the UK system, they are students with EAL (English as an additional language.

\section{References}

Atkinson, D. 2003. Writing and culture in the post-process era. Journal of Second Language Writing 12: $49-63$.

Badger, R. and G. White. 2000. A process genre approach to teaching writing. ELT Journal 54: 153 -160 .

Baker, E. 1994. Writing and reading in a first-grade writers' workshop: a parent's perspective. Reading Teacher 47: 372 - 377.

Bitchener, J. 2010. A Genre Approach to Understanding Empirically Based Thesis Writing Expectations. Wellington, New Zealand: Ako Aotearoa. https://akoaotearoa.ac.nz/download/ng/file/group-3300/a-genre-approach-tounderstanding-empirically-based-thesis-writing.pdf (accessed 12 Oct, 2016).

Bourdieu, P. and J. Passeron. 1990. Reproduction in Education, Society and Culture. London: Sage. Calkins, L. 1994. The Art of Teaching Writing, ( $2^{\text {nd }}$ ed.). Portsmouth, NH: Heinmann.

Calkins, L. 2007. Units of Study for Teaching Writing, Grades 3-5. Portsmouth, NH: Heinemann.

Carolina, S. 2009. Autores bilingües/bilingual authors: writing within dual cultural and linguistic repertoires. Education 130: 78-95.

Carson, J. and G. Nelson. 1996. Chinese students' perceptions of ESL peer response group interaction. Journal of Second Language Writing 5: 1 - 9 .

Chien, S. 2006. A study of cognitive and metacognitive strategies in the process of writing English as a second language: a cognitive approach. Paper presented at the Sig Writing Conference $\left(10^{\text {th }}\right)$, Antwerp, Belgium.

Dix, S. 2006. "What did I change and why did I do it?" Young writers' revision practices. Literacy 40: 3-10.

Dorn, L. and C. Soffos. 2001. Scaffolding Young Writers: A Writer's Workshop Approach. Portland, ME: Stenhouse Publishers.

Dyer, B. 1996. L1 and L2 composition theories: Hillocks' "environmental mode" and task-based language teaching. ELT Journal 50: 312-7.

Ellis, R. 2009. Task-based language teaching: sorting out the misunderstandings. International Journal of Applied Linguistics, 19: 221 - 246. 
The Impact of the Writers' Workshop Approach

Fink-Chorzempa, B., S. Graham and K. Harris. 2005. What can I do to help young children who struggle with writing? Teaching Exceptional Children 37: 64-66.

Fletcher, R. and J. Portalupi. 2004. Teaching the Qualities of Writing. Portsmouth, NH: Heinemann.

Ghanbari, B., H. Barati and A. Moinzadeh. 2012. Rating scales revisited: EFL writing assessment context of Iran under scrutiny. Language Testing in Asia 2: 83- 100.

Goodman, Y. and S. Wilde. 1992. Literacy Events in a Community of Young Writers. New York: Teachers College Press.

Graham, S. and D. Perin, D. 2007. A meta-analysis of writing instruction for adolescent students. Journal of Educational Psychology 99: $445-476$.

Graves, D. 1983. Writing: Teachers and Children at Work. Portsmouth, NH: Heinemann.

Graves, D. 1985. All children can write. Learning Disabilities Focus 1: 36-43.

Hadley, O. 1993. Teaching Language in Context. Boston: Heinle and Heinle.

Harris, K., S. Graham and L. Mason. 2006. Improving the writing, knowledge, and motivation of struggling young writers: effects of self-regulated strategy development with and without peer support. American Educational Association 43: 295 - 340.

Helsel, L. and D. Greenberg. 2007. Helping struggling writers succeed: a self-regulated strategy instruction program. Reading Teacher 60: $752-760$.

Honeycutt, R. 2002. Good readers/poor writers: an investigation of the strategies, understanding, and meaning that good readers who are poor writers ascribe to writing narrative text ondemand. PhD dissertation, North Carolina State University, Raleigh.

Hyland, K. 2003. Genre-based pedagogies: a social response to process. Journal of Second Language Writing 12: 17-29.

Jacobs, H., S. Zinkgraf, D. Wormuth, V.F. Hartfiel and J. Hughey. 1981. Testing ESL Composition: A Practical Approach. Rowley, MA: Newbury House.

Jasmine, J. and W. Weiner. 2007. The effects of writing workshop on abilities of first grade students to become confident and independent writers. Early Childhood Education Journal 35: 131-139.

McComiskey, B. 2000. Teaching Composition as a Social Process. Logan, UT: Utah State University Press.

Nunan, D. 1995. Language Teaching Methodology. London: Prentice Hall International.

Pachler, N., M. Evans and S. Lawes. 2007. Modern Foreign Languages: Teaching School Subjects 11 - 19. London: Routledge.

Pritchard, R. and R. Honeycutt. 2006. The process approach to writing instruction. In Handbook of Writing Research, eds. C. MacArthur, S. Graham and J. Fitzgerald, 275-292. New York: Guilford Press.

Ray, K. and L. Laminack. 2001. The Writing Workshop: Working through the Hard Parts (and They're All Hard Parts). Urbana, IL: National Council of Teachers of English.

Rogers, R. 2010. Incorporating metacognitive strategy training in ESP writing instruction: English for lawyers. English Language Teaching 3: 3-9.

Sheakoski, M. 2008. Writer's workshop for Elementary kids: Teach Prewriting, Writing, Revising, Editing, and Publishing Skills. http://suite101.com/article/writers-workshop-for-elementarykids-a61974 (accessed 12 Oct, 2016).

Shehade, A. 2011. Effects and student perceptions of collaborative writing in L2. Journal of Second Language Writing 20: 286-305.

Smagorinsky, P. 1987. Graves revisited: a look at the methods and conclusions of the New Hampshire study, Written Communication 4:331 - 342.

Smagorinsky, P., L. Johannessen, E. Kahn and T. McCann. 2010. The Dynamics of Writing Instruction: A Structured Process Approach for Middle and High School. Portsmouth, NH: Heinemann.

Smith, C.B. 2000. Writing Instruction: Changing Views Over the Years. http://www.ericdigests.org/2001-3/views.htm (accessed 12 July, 2016).

Smithson, M. 2008. Academic effects of writer's workshop. PhD dissertation, University of Liberty.

Tangpermpoon, T. 2008. Integrated approaches to improve students writing skills for English major students. ABAC Journal 28: $1-9$.

URL: http://mc.manuscriptcentral.com/rllj Email: N.Pachler@ioe.ac.uk 
The Impact of the Writers' Workshop Approach

Tompkins, G. 2002. Struggling readers are struggling writers, too. Reading and Writing Quarterly 18: $175-193$.

Troia, G. 2007. Research in writing instruction: what we know and what we need to know. In Shaping Literacy Achievement: Research We Have, Research We Need, eds. M. Pressley, A. Billman, K. Perry, K. Reffitt and J. Reynolds, 216-245. New York: Guilford Publications.

Vollmer, G. 2000. Praise and stigma: teachers' constructions of the 'typical ESL student'. Journal of Intercultural Studies 21: $53-66$.

Vollmer, G. 2002. Sociocultural perspectives on second language writing. ERIC Clearinghouse on Languages and Linguistics 25: 1 - 3.

Vygotsky, L. 1978. Mind in Society: The Development of Higher Psychological Processes. Cambridge, MA: Harvard University Press. 
Table 1 Pre-test post-test comparisons on components and total score

\begin{tabular}{|c|c|c|c|c|c|}
\hline $\begin{array}{l}\text { Paired Variables } \\
\qquad(N=31)\end{array}$ & $M$ & $\begin{array}{c}\text { Mean } \\
\text { difference }\end{array}$ & $\begin{array}{l}\text { Unpaired } \\
S D\end{array}$ & $\begin{array}{l}\text { Paired } \\
S D\end{array}$ & $\begin{array}{l}\text { Paired } t \text { test } \\
(d f=30)\end{array}$ \\
\hline Pre-Content & 21.55 & & 3.62 & & \\
\hline Pair 1 & & -2.71 & & 2.02 & $-7.47^{*}$ \\
\hline Post-Content & 24.26 & & 3.10 & & \\
\hline Pre-Organization & 14.39 & & 2.68 & & \\
\hline Pair 2 & & -1.48 & & 1.69 & $-4.89^{*}$ \\
\hline Post-Organization & 15.87 & & 2.64 & & \\
\hline Pre-Vocabulary & 14.19 & & 2.43 & & \\
\hline Pair 3 & & -1.00 & & 1.15 & $-4.82 *$ \\
\hline Post-Vocabulary & 15.19 & & 2.23 & & \\
\hline Pre-Language Use & 17.68 & & 2.26 & & \\
\hline Pair 4 & & -1.58 & & 1.69 & $-5.21 *$ \\
\hline Post-Language Use & 19.26 & & 2.41 & & \\
\hline Pre-Mechanics & 3.94 & & .58 & & \\
\hline Pair 5 & & -.29 & & .46 & $-3.50^{*}$ \\
\hline Post-Mechanics & 4.26 & & .62 & & \\
\hline Pre-Total Score & 71.74 & & 10.50 & & \\
\hline Pair 6 & & -7.065 & & 4.80 & $-8.20^{*}$ \\
\hline Post-Total Score & 78.80 & & 9.95 & & \\
\hline
\end{tabular}

* Significant at level $p<.01$ 
Table 2 Descriptive statistics and MANCOVA of post-test scores by proficiency group

\begin{tabular}{|c|c|c|c|c|c|}
\hline Dependent variable & Groups* & $n$ & $M$ & $S D$ & $F$ \\
\hline \multirow{4}{*}{ Post-Content } & Below Average & 11 & 20.91 & 2.26 & \multirow{4}{*}{$15.79 *$} \\
\hline & Average & 9 & 25.11 & 1.17 & \\
\hline & Above Average & 11 & 26.91 & 1.38 & \\
\hline & Total & 31 & 24.26 & 3.01 & \\
\hline \multirow{4}{*}{ Post-Organization } & Below Average & 11 & 13.73 & 1.27 & \multirow{4}{*}{$12.01 *$} \\
\hline & Average & 9 & 15.33 & 2.50 & \\
\hline & Above Average & 11 & 18.46 & 1.29 & \\
\hline & Total & 31 & 15.87 & 2.64 & \\
\hline \multirow{4}{*}{ Post-Vocabulary } & Below Average & 11 & 13.09 & .701 & \multirow{4}{*}{$17.65 *$} \\
\hline & Average & 9 & 14.89 & 1.76 & \\
\hline & Above Average & 11 & 17.55 & .93 & \\
\hline & Total & 31 & 15.19 & 2.23 & \\
\hline \multirow{4}{*}{ Post-Language Use } & Below Average & 11 & 17.00 & 1.00 & \multirow{4}{*}{$8.51 *$} \\
\hline & Average & 9 & 19.45 & 1.67 & \\
\hline & Above Average & 11 & 21.36 & 1.91 & \\
\hline & Total & 31 & 19.26 & 2.41 & \\
\hline \multirow{4}{*}{ Post-Mechanics } & Below Average & 11 & 3.73 & .47 & \multirow{4}{*}{$7.15 *$} \\
\hline & Average & 9 & 4.33 & .50 & \\
\hline & Above Average & 11 & 4.64 & .51 & \\
\hline & Total & 31 & 4.23 & .62 & \\
\hline \multirow{4}{*}{ Post-Total Score } & Below Average & 11 & 68.46 & 3.17 & \multirow{4}{*}{$25.42 *$} \\
\hline & Average & 9 & 79.11 & 6.41 & \\
\hline & Above Average & 11 & 88.91 & 4.91 & \\
\hline & Total & 31 & 78.81 & 9.96 & \\
\hline
\end{tabular}

* Significant at level $p<.01$ 
Table 3 Multiple comparisons of post-test component scores

\begin{tabular}{|c|c|c|c|}
\hline Dependent Variable & Groups (I) & Groups (J) & $\begin{array}{c}\text { Mean Difference } M D \\
(M D=\mathrm{I}-\mathrm{J})\end{array}$ \\
\hline \multirow{6}{*}{ Post-Content } & \multirow{2}{*}{ Below Average } & Average & $-4.20^{*}$ \\
\hline & & Above Average & $-6.00^{*}$ \\
\hline & \multirow{2}{*}{ Average } & Below Average & $4.20^{*}$ \\
\hline & & Above Average & -1.71 \\
\hline & \multirow{2}{*}{ Above Average } & Below Average & $6.00^{*}$ \\
\hline & & Average & 1.79 \\
\hline \multirow{6}{*}{ Post-Organization } & \multirow{2}{*}{ Below Average } & Average & -1.61 \\
\hline & & Above Average & $-4.73^{*}$ \\
\hline & \multirow{2}{*}{ Average } & Below Average & 1.61 \\
\hline & & Above Average & $-3.12^{*}$ \\
\hline & \multirow{2}{*}{ Above Average } & Below Average & $4.73^{*}$ \\
\hline & & Average & $3.12^{*}$ \\
\hline \multirow{6}{*}{ Post-Vocabulary } & \multirow{2}{*}{ Below Average } & Average & $-1.79^{*}$ \\
\hline & & Above Average & $-4.46^{*}$ \\
\hline & \multirow{2}{*}{ Average } & Below Average & $1.79^{*}$ \\
\hline & & Above Average & $-2.66^{*}$ \\
\hline & \multirow{2}{*}{ Above Average } & Below Average & $4.46^{*}$ \\
\hline & & Average & $2.66^{*}$ \\
\hline \multirow{6}{*}{ Post-Language Use } & \multirow{2}{*}{ Below Average } & Average & $-2.44^{*}$ \\
\hline & & Above Average & $-4.36^{*}$ \\
\hline & \multirow{2}{*}{ Average } & Below Average & $2.44^{*}$ \\
\hline & & Above Average & -1.92 \\
\hline & \multirow{2}{*}{ Above Average } & Below Average & $4.36^{*}$ \\
\hline & & Average & 1.92 \\
\hline \multirow{6}{*}{ Post-Mechanics } & \multirow{2}{*}{ Below Average } & Average & -.61 \\
\hline & & Above Average & $-.91^{*}$ \\
\hline & \multirow{2}{*}{ Average } & Below Average & .61 \\
\hline & & Above Average & -.30 \\
\hline & \multirow{2}{*}{ Above Average } & Below Average & $.91^{*}$ \\
\hline & & Average & .30 \\
\hline \multirow{6}{*}{ Post-Total Score } & \multirow{2}{*}{ Below Average } & Average & $-10.66^{*}$ \\
\hline & & Above Average & $-20.46^{*}$ \\
\hline & \multirow{2}{*}{ Average } & Below Average & $10.66^{*}$ \\
\hline & & Above Average & $-9.71^{*}$ \\
\hline & \multirow{2}{*}{ Above Average } & Below Average & $20.46^{*}$ \\
\hline & & Average & $9.71^{*}$ \\
\hline
\end{tabular}

* Significant at level $p<.01$ 